\title{
On the Origins of Welfare Stigma: \\ Comparing two social assistance schemes in rural China
}

\author{
Mianguan Li and Robert Walker
}

\begin{abstract}
While stigma has often been implicated in the low take-up of benefits, its aetiology is not well understood. Drawing distinctions from earlier research, notably differentiating personal, social and institutional stigma, the article explores how each is related to each other and how each alone, and in concert, is framed by political and local culture. As case-studies, two of the world's largest social assistance schemes, Dibao and Wubao, are compared in a village in south central China based on ethnographic work with recipients, village cadre charged with implementing both schemes, and non-recipients. In explaining the reasons for the very different level of stigma attaching to each scheme, the article unearths processes of salience to academics and policymakers.
\end{abstract}

Keywords: welfare stigma, origins, social assistance, rural China 


\section{Introduction}

There is a long history of research on stigma, shame and social assistance, much of it concerned to explain poor targeting and the low take-up of benefits (Blank \& Ruggles, 1996). Discussed initially in the context of the Elizabethan Poor Law in Britain, the phenomenon has been found across time and cultures, but the specific processes and mechanisms are still not well understood (Chase \& Bantebya-Kyomuhendo, 2014; Walker, 2014).

Research points to multiple factors causing recipients of social welfare to feel ashamed: the equating of poverty with deficiencies in behaviour and character (Stuber \& Schlesinger, 2006); undignified treatment meted out in the implementation of social assistance (Edmonds, 2005); and unequal power relations in interactions between recipients and others (Lister, 2004; Roelen \& Gassmann, 2011). Van Oorschot (1991, 2006) has also speculated about the importance of cultural and policy context as well as the design of social assistance schemes, topics addressed directly in the current article which exploits the rare opportunity to compare the generation of stigma with respect to two social assistance schemes within the same cultural context. Specifically, this article explores how the framing, design and delivery of social assistance can work together with culture to shape the stigma experienced by recipients.

Chinese social security has been reconstructed since the mid-1990s in response to new social problems caused by transformation to a market economy. The system comprises social insurance, social assistance and public services with a key feature 'duality', meaning substantial differences between rural and urban areas with typically more generous provision in urban areas (Liu et al., 2016). This study is set in rural China where two social assistance schemes were chosen for comparison: Dibao (Minimum Living Security System), the largest social assistance scheme in the world, reaching 46 million people in rural China in June 2016 (Ministry of Civil Affairs, 2016a) and Wubao ('The Five Guarantees System', now officially renamed as 'Relief for the Extremely Poor'). Wubao was the first social assistance to be implemented in rural China and some 60 years later still benefits over five million people in 2015 (Ministry of Civil Affairs, 2016b). Fieldwork was conducted in a village where people shared the same local culture meaning that many exogenous variables are controlled by design. This permits exploration of how different policy designs and implementation structures combine and differentially interact with a common culture to generate varying degrees of stigmatisation. 


\section{On the types and causes of welfare stigma}

Stigma has long been recognized to diminish the well-being of welfare recipients as well as imposing limits on benefit take-up (Besley \& Coate, 1992). Precisely why stigma is associated with welfare provision however is contested. Williamson (1974) groups the competing reasons into four:

1. Personal characteristics of recipients that are considered anti-social and undesirable;

2. Recipients' own perception that their dependence on welfare affords them lower status than being economically self-sufficient;

3. Negative labelling of social assistance claimants by others;

4. Humiliating treatment, actual, perceived or both, during the application process and /or subsequently

Although Williamson's was writing forty years ago, his analysis remains pertinent. However, whereas Williamson treats stigma as a unitary concept, others have distinguished three types of stigma, personal, social and institutional, that have different causes (Baumberg, 2013; Walker, 2014).

Personal stigma refers to the widely-reported phenomenon that welfare recipients themselves feel that claiming benefits is shameful (Baumberg et al., 2012; Edmonds, 2005; Hernanze et al., 2004). Two kinds of explanation for personal stigma have been proposed by researchers: self-comparison and lack of reciprocity. The first describes the shame felt when welfare recipients contrast their present status, often taken to be symbolic of 'personal failure', with their ideal (Walker, 2005). The second equates benefit receipt with state charity; whereas most social interaction involves reciprocity, charity makes no such demands being a 'freely given gift' while simultaneously denying recipients the status and respect that reciprocity affords (Spicker, 1984; Stuber \& Schlesinger, 2006). Personal stigma has been implicated in many studies and is one important reason for low take-up of social assistance (Hernanz et al., 2004; Oorschot, 1991).

Social stigma relates to the attitudes and behaviour of non-recipients which in turn helps to shape personal stigma both directly, as when welfare recipients are humiliated, and indirectly through affecting their self-evaluation (Lister, 2004). Social stigma may be least severe in societies where poverty is believed to be the result of structural factors and people have a strong sense of social rights. Elsewhere, when poverty is attributed to personal failure, recipients tend to be labelled as 'wasters', 'lazy', 'dependent' or worse (Baumberg et al., 2012; Walker, 2014). Besley \& Coate (1992) employ the term 'statistical discrimination' to summarize this mechanism of social stigma through which welfare claimants are negatively categorized on the presumption that they all fail to meet societal expectations. Social stigma is likely to be most prevalent in countries where much of the population opines that the main reason for poverty is 'laziness and lack of willpower'; these include China and Japan in the East and US and Australia in the West (Walker, 2014: 
134). Nevertheless, social assistance can be heavily stigmatised in social democratic countries because its coverage is so residual and recipients are thereby atypical and often socially excluded (Simpson \& Walker, 1993). Additionally, the fact that welfare recipients are often unable adequately to perform their social roles as parents, citizens, or organization members due to lack of resources (Chase \& Bantebya-Kyomuhendo, 2014: 2) contributes to the perception of a bifurcated society comprising active citizens and welfare recipients, the latter being labelled as 'losers' (Lister, 2004; Jo, 2013).

Institutional stigma has its source in the framing, design and implementation of social assistance policies (Walker, 2014). Stuber and Schlesinger (2006: 944), for example, suggest that 'perceptions of stigma are determined, in part, by the nature of the benefit that is being provided, noting that social assistance is widely reported to be more stigmatising than universal benefits (Williamson, 1974). Politicians, in seeking to reconcile competing pressure to prevent destitution while lowering taxation, often adopt the language of deserving and undeserving to signal that only the neediest will be helped while abuse will be prevented (Yaniv, 1997; Walker, 2005).

Turning to design, stigma or shaming is used to contain the problem of moral hazard by providing minimal benefits to prevent people choosing welfare over work, and by policing eligibility very publicly. In urban China, home visits are used to seek out 'profligate' spending on basic consumer durables; in South Korea, applicants are obliged to demonstrate eligibility by supplying evidence that relatives will not support them; while, in Britain, 'Spot the Cheater' campaigns have put all benefit recipients under public scrutiny (Walker, 2014).

In terms of implementation, Gray (2005) describes three pathways by which stigma is conferred on claimants. First, on application, claimants confront suspicion of weakness, laziness and fraud while feeling that their strengths are rarely recognised. Waiting times are often long, security checks officious and accommodation inadequate (Krause, 1996; Wright 2003). Nicolas and Baptiste (2001: 304), for example, report that most women applicants of public assistance in the US described 'the process of entering the system as "degrading," "devaluing," "dehumanizing," and "belittling”.' Secondly, in their interaction with caseworkers, recipients find that they are not believed, that they are treated with contempt, coerced and even abused by often overworked and low paid staff who are sometimes openly envious of the benefits being paid out (Finn et al., 2008; Rank, 1994). Thirdly, social assistance recipients risk stigma in the community. Gray (2005) notes the humiliation encountered due to the public visibility of Food Stamps (now, Supplemental Nutrition Assistance Program, SNAP) in the US, while workfare recipients in community schemes in, for example, New York and Seoul are compelled to wear distinctive uniforms.

The three-fold distinction between personal, social and institutional stigma 
proves to be a helpful device in understanding the distinctive experiences of recipients of Wubao and Dibao.

\section{Method}

The research was conducted between July 2014 and November 2015 in a village in south-central China which we call Stone-bridge with ethical approval granted by the first author's university. To maintain anonymity, all names are pseudonyms and figures are rounded. The population of 2,500 in 2014 was divided between 700 households. One person in ten was aged over 60 (elders) while almost one in five were children aged under 14 years old. Households were divided into 11 quasi-administrative village groups which varied in size by a factor of four. These groups were involved similarly in the administration of Dibao and Wubao.

Average annual household income of 3450 yuan RMB (about £350) was typical of the county and Stone-bridge was designated as 'poor' by the provincial government. Benefits paid through the two social assistance schemes, Dibao and Wubao, constituted between a third and a half of village incomes.

The first author had established research links in the village over many years. Fifty-six semi-structured qualitative face-to-face interviews were conducted complemented by eighteen telephone ones with an overall response rate of 86 per cent. All interviews were conducted in the local dialect, audio recorded, and translated into Mandarin Chinese for analysis with quotations subsequently translated into English for publication.

All 12 Wubao recipients and 28 of the 216 Dibao recipients were interviewed along with 34 non-recipients including six of the seven village cadres comprising the village committee (the seventh refused) so as simultaneously to explore personal, social and institutional stigma. Respondents were sampled using a systematic, iterative snowballing methodology with assistance from three villager informants. A person randomly selected from the list of Stone-bridge residents was first interviewed and also asked to suggest a person likely to receive benefit. The person named was interviewed and then, their neighbour who was also asked to suggest a further potential recipient. Village cadres were separately identified.

\section{Table 1 Here}

The age profile of the sample (Table 1 ) is as anticipated in that, reflecting differing eligibility criteria, all Wubao recipients were aged over 60 compared to just 29 per cent of Dibao recipients. The fact that most Dibao recipients were aged over 46 years reveals a local departure from the national policy intended to support individuals rather than families. The substance of these matters is discussed below. 
As is commonly the case in rural China, many younger villagers had moved to cities as migrant workers but necessarily remained registered in the village under the official Hukou registration system which determines where a person is allowed to live and to which public services they have access (Wang and Liu, 2016). This explains why non-recipient respondents were correspondingly older than the village average recorded in official records. The finding that about three-fifths of respondents were male mirrors the eligibility criteria of Wubao and payment of benefit to male heads of household. There was also a tendency, resisted by the lead author in the field, for households to nominate a male as respondent.

\section{objectives, design and implementation of Dibao and Wubao}

The Five Guarantees Scheme (Wubao) was established in the mid-1950s while the Minimal Living Security System (Dibao), which was rapidly adopted by cities after its introduction in Shanghai in 1993, became universal in rural areas after 2007 when central government funding was substantially increased. Both schemes are administered at village level. Applications are received by quasi-administrative village groups, leaders of which - with village representatives - make recommendations to the Villagers' Committee that decides on awards, subject to Township approval. Targeting, as legislation prescribes and as actually delivered, differs with significant implications for the subjective experience of recipients.

\section{Wubao}

Wubao is not designed as a comprehensive social assistance system but rather to meet the needs of certain kinds of people who live in poverty. The target groups are defined in terms of demographic characteristics which assume the status of identity groups in Chinese cultural politics and serve to exclude from eligibility most people experiencing poverty. The dual nature of Wubao, defining eligibility in terms of the conjunction of economic and identity status, was present from its introduction.

Wubao was a product of both the scale of persistent poverty and the collectivization of agriculture in rural China stemming from the First Five Year Plan (1953-7). While a social security system was established in cities in 1951, no comparable system was introduced in rural areas creating demands for some basic provision to prevent mass starvation. Land reform transferred ownership from individuals to collectives as a critical phase in the transformation to socialism such that, by 1956, over 96 per cent of 'peasant households' belonged to cooperatives (Wong, 1998: 50). The collectives were soon generating the resources necessary to underwrite the basic needs of the most vulnerable allowing the central government to lay the foundations of the Five Guarantees Scheme in the Outline of National Agricultural Development 1956-1967, which decreed that:

Agricultural cooperatives should make suitable arrangement for persons who are widowed or orphaned and without support from family, and guarantee their 
food, fuel, clothing, education and burial. (National People's Congress, 1957, item $30^{\text {th }}$ )

These five guarantees became a fundamental component of policy in rural China with Wubao established for unsupported widows, widowers, singletons and orphans without the resources to feed themselves. In 2015, the legacy of this original identity-targeting mechanism was still branded on the memory of villagers:

In 1960s, every family in our village was poor, but not everyone could get Wubao......The conditions were so strict that few of people could meet the threshold. Only elders without sons or daughters, or children without parents, or the disabled without any working ability could get the benefit. (Li T.K., villager, over 75 years old)

Wubao was modified several times after the collectivist era during the Reform and Opening-up periods in China but most importantly in 2006 when financial responsibility was transferred from collectives to central and local government (Gao \& Huang, 2007). This reform, which facilitated the expansion of the scheme, altered the five guarantees with fuel being subsumed under the broader category of housing, medical care being added, and education being more clearly bracketed as for orphans only. The 2006 Regulations established the following eligibility criteria, the 'Three Nos':

Elders, the disabled, and children who meet all the following conditions: first, incapability of work; second, no income; third, no persons statutorily required to provide maintenance. (Ministry of Civil Affairs, 2006)

Village cadres have no discretion in applying these criteria not least because people meeting them are well known to villagers. Consequently, only 12 people, all widows or widowers, received Wubao in Stone-bridge in 2015, each getting 250 yuan RMB (about £30) per month. Numerous other families were excluded:

Frankly speaking, elders without sons or daughters are pitiful because they cannot work and cannot get any support from other family member, and the only hope for them is the benefit from Wubao. But it is even harder for some families with sons or daughters. For example, one family with three school-age children have had to go into debt to support their children's education, given the father is disabled. But this family cannot get the benefit [because they have offspring]. (Li Q.H., Leader of Villagers' Committee)

\section{Dibao}

As already noted, Dibao became the dominant social assistance in rural China from 2007. It is jointly funded by central and local government and administered by village committees. Unlike Wubao, Dibao is formally targeted on income rather than identity or demographic group with the legislation making clear its anti-poverty intent: 
The aim of rural Dibao is to reach all people who live in poverty in rural China, alleviating poverty in a stable, durable, and efficient way. (State Council, 2007)

In theory, therefore, everyone whose income is below Dibao threshold has the right to receive benefit irrespective of identity. In 2014, the per capital threshold in Stone-bridge, which is set annually by the county government, was 1,600 yuan RMB per year (£168). However, the county also stipulates the number of awards that can be made and the allocation (200 individuals) was insufficient to meet the actual level of need. Faced with this conundrum, the village committee chose not to pay benefit to all people living in families below the threshold as stipulated but instead to make one payment to each household deemed to be eligible, thereby maximising the number of families who benefit (Li \& Walker, 2016). Each Dibao award was worth 133 yuan per month, about half that of Wubao.

The different characteristics of the two social assistance schemes, summarised in Table 2, were widely recognised in the village. This is important because it directly influenced the types of stigma imposed on recipients:

Dibao and Wubao are different things. Wubao is a policy for special people like widows or widowers, while Dibao is not. Dibao is for everyone who is poor, no matter how you fell into poverty. (Xiao H., villager, female, 55 years old)

Table 2 Here

\section{Differentiating stigma}

The different goals and design of Dibao and Wubao interact with village culture to affect the relative importance of the three kinds of stigma identified in the literature reviewed above.

\section{Institutional stigma}

While institutional stigma is a product of the framing, structure and delivery of benefit (Walker, 2014), its precise expression reflects the conjunction of policy and culture. Different histories shape the framing of both schemes. Wubao is a product of collectivism dating from a time when local needs were met locally at considerable personal cost. In contrast, Dibao is an example of modernity, an income-based scheme that was introduced when poverty had come to signify personal failure rather than, as in the Maoist era, a sacrifice made for the common good. Moreover, Dibao has been co-opted locally for purposes of social control rather than poverty relief (Li \& Walker, 2016). These framings affect the design and implementation of Dibao and Wubao and their social acceptability.

Although Wubao and Dibao both target low incomes, Wubao recipients 
additionally have to meet the 'Three Nos' criteria. These additional conditions mean that, while Wubao targets the 'poorest of the poor', it also excludes some of the very poorest. With these restrictive rules, Wubao divides villagers making recipients special and conspicuous for culturally the worst of reasons:

Wubao is a special policy just for those special persons, and we don't want to be the special ones. (Li J.Y., villager, female, over 65 years old)

Frankly speaking, to be a Wubao household is not what I want. There was no Dibao system in the past, so I had to apply for Wubao. But now, I would like to give up Wubao and apply for Dibao. My request was refused by village cadres; they said that if I quit Wubao for Dibao ... other villagers would have less opportunity to receive it. ......If I quit the Wubao scheme, I would get less money. But I am still willing to do so because people would stop addressing me as 'old bachelor' [which is insulting]. (Qin X.Z., Wubao recipient, over 68 years old)

Because any person meeting the 'Three Nos' criteria is likely to be poor, Wubao clearly targets financial need but, understood from the perspective of culture, this threshold has another totally different meaning: having 'no family support'. In Chinese culture, having no descendant is the worst of the 'three unfilial acts', for it means not only failing give purpose to one's own life, but preventing the continued existence of one's family. Although this doctrine has been weakened in modern times, illustrated by the growth in 'dual income, no kids' (DINK) families in urban areas (Wang, 2009), the idea of procreation as a basic duty punishable within the extended family remains very influential in rural China. While logically it is not Wubao that causes recipients to have no descendants, having no descendants entitles them Wubao and adds to its stigma. In combination, childlessness and Wubao create a heavily stigmatised cultural identity that acts as a deterrent to applying for benefit, sometimes powerful enough for people to resist overtures from the village committee:

In the past, we didn't have much collective resource to take care of Wubao recipients, so we just involved a few single elders... But now, expenditures on Wubao are from government, so we would like to expand the coverage and involve some who are disabled. But, when we asked some of them to apply for Wubao, they got to be angry and refused our suggestion rudely. It is very strange, and $\mathrm{Li}$ Z.M. is an example. (Xi X.H., major member of Villagers' Committee, female, nearly 50 years old)

This 'very strange' behaviour was explained by Li Z.M. himself when interviewed:

I don't know whether I can apply for Wubao. Even if I can, I am not willing to do so. Which kind of people are Wubao households? Everyone knows that only those who have no sons and daughters would become Wubao households. Families without descendants will disappear in the future, and that is a dreadful thought to behold. (Li Z.M., disabled, Dibao recipient, about 40 years old) 
Dibao is very different. While the regulations circumscribe who may receive benefit defining, for example, 'family members' and what counts as family income (e.g. awards under the One Child Policy, medical aid and students' scholarships are excluded), these criteria relate to socioeconomic status and do not distinguish special groups of people. This distinction was widely recognised:

It is nothing (special to get Dibao). Although some families are rich now, they would fall into poverty if they encountered a problem requiring great expenditure, such as an unexpected serious disease. It is a valuable institution for every peasant. I think we should not consider recipients as a special group because you may need it one day in the future. Of course, benefit is distributed to people who are not poor which is another story. (Xiao H., villager, female, 55 years old)

In sum, Dibao does not carry the same innate stigma as Wubao. However, Xiao H.'s words point to the importance of implementation which adds further to the distinctiveness of Dibao and Wubao (see below). Both schemes include a review of circumstances that is expected to lead to a turnover of recipients. So, for example, under Wubao, a young person reaching the age of 16 would cease to be eligible as an orphan. However, because in many villages the Wubao scheme is paid only to elders without family support, recipients tend to receive the benefit until they die. While this is clearly appropriate, since without Wubao their financial circumstances might become desperate, the permanence of benefits adds to the divisiveness of Wubao by creating a separate welfare 'class' of beneficiaries different from other villagers. Not only are some members of this class stigmatised for their failure to procreate, all are considered to be paupers, people who are incapable of making good and forever reliant on society and others' charity.

Once you become a Wubao household, you will be a Wubao household forever. The hat of 'Wubao household' will be put on your head in all your life, and once the hat is on your head it means that you cannot feed yourself and you are a loser. (Ying S.H., Senior member of Villagers' Committee)

Dibao, on the other hand, is an annually adjusted programme meaning that recipients will be different every year although in practice longer-term recipients confronting sustained financial insecurity are likely to constitute a growing proportion of the total. Nevertheless, the perception was that Dibao is a temporary benefit tiding people over difficult circumstances that is available to anyone who might encounter hardship (see respondent Xiao H cited above).

For Dibao recipients themselves, the annual adjustment must lead to some ambivalence: on one hand, there is the risk of losing benefit; on the other hand, the stigma of dependency is reduced, and the chances of social exclusion lessened. This ambivalence is clear in the following quotation:

It is true that some of recipients, including me, cannot get the benefit 
anymore because of the adjustment. But in my opinion, the adjustment is necessary and reasonable as long as it is implemented accurately. Without adjustment, Dibao system would become like Wubao, and people would look down on Dibao recipients as like they do Wubao recipients. (Yu D.M., Dibao recipient, female, over 45 years old)

The proviso in the above quotation that the adjustment should be accurately implemented is revealing because, as is explained in the next section, Dibao is very often not administered per regulations leading to bad targeting (Li \& Walker, 2016). While the principle of annual review might be widely supported, mal-administration is not. Equally, because Dibao awards are not infrequently made to reward good behaviour rather than to address need, Dibao can sometimes be seen as a badge of high social standing rather than a mark of personal failure (Li \& Walker, 2016). The readjustment increases the incentive for such good behaviour since it annually frees up Dibao resources to be used in this way.

\section{Social stigma}

Institutional stigma may be amplified or muted by social norms as expressed in the attitudes and behaviour of the public towards welfare recipients. Individual welfare recipients may be more or less sensitive to social stigma with some internalising the same values and others not. Irrespective of whether social stigma is internalized to be felt personally, the labelling involved creates a generally negative environment that can frame the lives of welfare recipients.

While Wubao has its origins in the collectivist era when mutual support was encouraged and people in poverty were sometimes favoured politically, the historic antipathy towards poverty remains strong; poverty is described as 'the greatest of evils' in the Confucian 'Book of Rites'. Therefore, although villagers often looked on Wubao recipients with mixed emotions, the social stigma of poverty was generally added to that attaching to childlessness. The financial circumstances of beneficiaries were self-evidently desperate but equally villagers often felt that there must be some character flaw, some deficit, to cause the destitution experienced by Wubao recipients. Many referred to the paradox inherent in the traditional saying 'kelian zhiren biyou kehen zhichu' that is sometimes translated as 'there is reason to despise those who could be pitied':

I know that Wubao households are really pitiful. No one would deny that.

But, as we always say, 'there is reason to despise those who could be pitied'.

Take Li Z.T. as an example. He was so lazy when we worked for the cooperative together and he always went gambling and got heavily into debt. I was sure that he would become a Wubao household when he got old. You see, it has come true. In my opinion, he is an irresponsible person not only for himself but also for the society. (Li T.M., villager, about 70 years old)

In the eyes of common villagers, recipients of Wubao were often considered to 
be 'losers', the 'dregs of society' and 'pitiful' meaning both disgraceful and pathetic. Some parents even used Wubao recipients as negative role models:

I always educate my son that if he does not study hard, he will not get a good job nor not get married. So, he will become a Wubao household like Qin X.Z.. That would be a disgrace not only for him but also for our whole family. (Jiang J.X., villager, female, about 40 years old)

The stigma against Wubao was so severe that it resulted in social exclusion, causing recipients often to experience great loneliness:

Although I live in the centre of the village and many neighbours live around me, I almost make no contact with them. Even at the Spring Festival, few villagers come to me and say 'Happy New Year'. One reason maybe that I am so poor and they gain nothing in return from meeting with me. And the other reason would be I am a Wubao household, and they look down upon me. (Li Q.Y., Wubao recipient, over 66 years old)

Li Q.Y.'s reasoning was confirmed by non-recipients:

I don't mean that Wubao recipients are separate from us because they really need help from us and society, but it is true that we have less interaction with them than with others, although we provide help for them sometimes as neighbours. First, it is not necessary for us to interact with them. Secondly, there are reasons for everyone who becomes a Wubao household and we don't want those factors influence our family members, especially our children. (Ying Y. H., villager, female, about 35 years old)

In marked contrast, the profound social stigma imposed on Wubao recipients was largely absent with respect to Dibao, despite villagers' general antipathy towards poverty. Paradoxically this may partly be due to the maladministration of Dibao which has been commandeered as an instrument of village governance to effect social control and order rather than primarily to mitigate the effects of poverty (Li \& Walker, 2016). In Stone-bridge, Dibao was allocated to four kinds of recipient:

1. People in demonstrable, unredeemable poverty caused by something like profound disability;

2. Relatives and friends of village cadres/elites who might or might not be poor but who received benefit based on social status, reciprocity and the promise of political support;

3. Village elites and common villagers who similarly received benefit not due to poverty but as a reward for, or encouragement of, 'good behaviour';

4. People deemed 'trouble makers' by the local cadre who had demonstrated their willingness to complain to higher authorities but who could be 'bought off' through the payment of Dibao.

It will be evident that only the first group carries the unqualified stigma of poverty, the others exhibit a positive status albeit slightly tarnished by the taint of 
corruption. Moreover, in a Chinese rural context held together by a network of mutual obligations, corruption is often understood and condoned as a manifestation of guanxi, a traditional form of social currency. Hence, to the extent that receipt of Dibao is evaluated based on ability, personality or behaviour, the outcome is broadly positive, the negative consequences of any poverty being offset by the positive associations of good social behaviour and high guanxi and social influence.

I don't feel something special when I talk to my neighbours even though I benefit from Dibao. If you ask anyone you meet on the road 'would you like to get Dibao', the answer would be 'yes'. Since everyone wants to get the benefit, no one would laugh at the recipients. (Liu X.Q., Dibao recipient, 64 years old)

This is not to say that there was universal approval of Dibao being abused:

How do I evaluate the recipients of Dibao? It depends. Some people should get it, such as the disabled. However, some of recipients should not get it because they are not poor. I know that they get the benefit because they are related to village cadres or previous village cadres. This is wrong, and I have informally told them so. (Wang X.M., villager, about 40 years old)

However, people with such reservations were quite often dismissed as expressing sour grapes. Moreover, the belief that anyone could receive Dibao based on good behaviour or good connections seemed to achieve the social harmony sought by the village cadre. Such complex machinations contribute further to destigmatizing Dibao (while helping to explain its poor targeting [Li \& Walker, 2016; Golan et al., 2014]). In contrast, the shame of poverty adds to the social stigma of Wubao; so strong is contempt for Wubao that it has no value as a tool of social control to be used by village cadre: nobody wants to be a Wubao household.

\section{Personal stigma}

The stigma felt personally by benefit recipients is a complex amalgam. It fuses social and institutional stigmatisation with individuals' own values and sensibilities that are themselves partly shaped by social norms including stigmatisation. The more that recipients align themselves with the social values, the more stigmatisation is experienced as shame with all the negative consequences documented by others (Tangney \& Dearing, 2003; Walker, 2014).

In Stone-bridge, Dibao was generally viewed as a positive good, a community resource often enjoyed by the worthy and influential. Applications for Dibao far exceeded awards which is explicable in terms of the balance between two kinds of shame, that attached to poverty, and that attributable to injustice (Li \& Walker, 2017). People, knowingly ineligible, claim Dibao with little sense of shame or guilt because it has become the accepted norm. On the other hand, the stigma associated with poverty has perhaps increased over time with personal financial success now being encouraged by national government while economic failure is despised. This was certainly the perception of the comparatively few people who claimed Dibao out of 
need. They considered themselves to have failed when measured against their own aspirations and those of their neighbours:

Earning much money is the best indicator of success and if you cannot do that, you will be a loser. I am a loser as I cannot feed myself, but have to wait for assistance from government. (Wang Z., 55 years old, Dibao recipient).

People in poverty who applied for Dibao explained that they had no alternative but to do so despite it making them feel 'uncomfortable'. Shamed by the confession of poverty and the failure that Dibao represented, they were seldom comforted by the fact that Dibao was received by many people who were much better off than they were; this merely drew attention to their low income and limited guanxi:

Dibao always makes me uncomfortable but I must apply for it every year because I have no choice. You know, I just have one hand now and cannot do any heavy work to earn enough money to feed myself and my daughter. (Hu J., Dibao recipient, 43years old)

As noted earlier, Wubao recipients also experience a deficit of guanxi and the shame of both being poor and needing state welfare. But additionally, all the recipients interviewed reported belonging to a special group of people defined in negative and derogatory terms. For Wubao recipients, social stigma translated directly into personal stigma that applied not only to their economic circumstances or even their behaviour, but to their sense of self. This is personal stigma experienced as shame.

I don't like getting Wubao, but I don't have any other choice!....A lot of people think that I am pathetic, while others think that I deserve it because I did too many wrong things when I was young. I agree that it is my destiny to be a Wubao household.......The only thing I wait for is death. (Li Z.T., recipient of Wubao)

To summarise, stigma associated with Wubao is more severe than for Dibao, and cumulative leading at a personal level, to the negation of self; at a social level to exclusion; and at an institutional level to cultural marginalisation (Table 3). In contrast, Dibao is generally viewed as inclusive in that it was potentially available to all; ironically stigma was experienced only by recipients who were truly eligible for benefit who carried and internalised the stigma attached to being poor.

\section{Table 3 Here}

\section{Reflections and conclusion}

This article has explored the interrelationships between the various forms of stigma (personal, social and institutional) associated with the receipt of social assistance benefits. It has also considered the influences likely to affect them, notably the framing, design and delivery of benefits as they interact with local culture and social and individual expectations. While appertaining to just two social 
assistance schemes (albeit very large ones) observed in a single village in China, the findings should give pause to generic assertions as to the nature and causes of welfare stigma.

The study nonetheless confirms the merits of Williamson's 1974 typology of causation: personal characteristics; status differentials; labelling; and humiliating treatment. The first three sets of causes clearly apply to Wubao: childlessness as a despised characteristic; poverty as a symbol of economic failure; and labelling as irresponsible. Moreover, while these causes were less evident in the case of Dibao, because villagers often do not perceive it to be an income-based benefit, they do apply with respect to those recipients who were actually poor. Space precluded detailed consideration of the humiliating treatment meted out to recipients as a source of stigma. However, this has been well documented elsewhere (Chen et al., 2017; Li \& Walker, 2017).

The study similarly affirms, as predicted by van Oorschot (1991), the importance of both culture and policy context in shaping stigma. It is traditional rural culture that makes the targeting of Wubao towards elders without family support so toxic. This cultural combination is evident in many countries in the developing world that are introducing minimal social protection schemes for the first time and seems to be re-emerging in advanced urban economies (NIA, 2011; Span, 2013). Culture, too, combined with hierarchical, authoritarian policy structures, allowed Dibao to be captured as a governance tool, severely curtailing its value as an anti-poverty measure but reducing the social stigma attached to it. Elites, who exploit social assistance for personal and other ends, are similarly not unknown outside of China (Sim et al., 2015; Pellissery \& Mathews, 2014). However, it is the unique conjunction of policy design (very specific identity targeting) and culture (the social stigma attaching to childlessness) that prevented Wubao from being commandeered for illicit purposes; village cadres had minimal discretion in targeting benefit while the sums of money involved were insufficient to offset the shame of being a Wubao household.

The utility of Baumberg's (2012) three-fold categorisation of stigma is similarly demonstrated. Dibao and Wubao are differentiated with respect to the different kinds of stigma and the ways in which they interact. In the case of Wubao, stigma is cumulative, a phenomenon commonly reported elsewhere (Pellissery et al., 2014). Heavy institutional stigma (a product of historic collectivist funding, negative perceptions of poverty and selectivity based on identity targeting) is reinforced by social stigmatisation. The latter comprises self-evident contempt for, and active discrimination against, aged and childless recipients who themselves generally accept this negative social evaluation. Because of this accumulation, and despite categorical targeting, Wubao is much more heavily stigmatised than Dibao.

One might have expected Dibao to have been heavily stigmatised. It is selective, nominally targeted on poverty and was introduced to benefit people 
experiencing poverty at a time when poverty was much despised. Indeed, institutional stigma is evident in the imposition of tough eligibility criteria and public scrutiny. However, social stigma is countered by the temporary nature of the support and by national rather than local funding (Simpson \& Walker, 1993; Michalopoulos, 2004.) It is further countered by the perception that Dibao is a public resource, available to everyone, even those not experiencing poverty. The stigma felt by recipients varies per the route through which they are accorded benefit. So, whereas, for Wubao recipients, the stigma of benefit receipt adds to the shame of poverty, this is less so for Dibao recipients.

Finally, the study introduces a couple of paradoxes that warrant attention. First, it is widely assumed that categorical targeting is less stigmatising than detailed means-tests; universal benefits are similarly considered to be more status-protecting than income-selective ones (Walker, 2005). Dibao and Wubao demonstrate the reverse pattern and for two reasons. First, targeting by social category rather than circumstance can signal permanence, long-term receipt, dependency and the creation of a welfare class. Villagers saw Wubao this way and disliked it. Secondly, Wubao targeted heavily stigmatised groups and this stigma transferred to Wubao itself.

The second paradox is that stigma attaching to Dibao is much reduced by what might be called corruption. Rather than, as intended, being a highly selective scheme personally benefiting only people who are extremely poor, it is also received by other families, many of whom would be ineligible on income grounds. The political and cultural rationale for this phenomenon is explained briefly above and in detail elsewhere ( $\mathrm{Li} \&$ Walker, 2016). It is not that the effectiveness of Dibao is improved by maladministration; it reduces stigma but massively lessens the resources reaching people in poverty. Rather, the paradox demonstrates the importance of achieving an appropriate fit between policy objectives and cultural realities rather than assuming that an 'off-the-shelf' policy design will work anywhere. It is perhaps less surprising, though, that villagers in Stone-bridge preferred a scheme that could meet villagers' expectation of local culture, and that cultural factors would matter in design and implementation of social policy.

\section{Reference}

Baumberg B (2013) Is ‘the paradox of redistribution' dead? Inequalities, 27th June. [https://inequalitiesblog.wordpress.com/2013/06/27/is-the-paradox-of-redistributi on-dead/].

Baumberg B, Bell K and Gaffney D (2012) Benefits Stigma in Britain. London: Turn2Us.

Besley T and Coate S (1992) Understanding welfare stigma: Taxpayer resentment and statistical discrimination. Journal of Public Economics 48: 165-83.

Blank R and Ruggles P (1996) When do women use AFDC and food stamps? The 
dynamics of eligibility vs. participation. Journal of Human Resource, 31(1): 57-89.

Chase E and Bantebya-Kyomuhendo G (eds.) (2014) Poverty and Shame: Global experiences. Oxford: Oxford University Press.

Chen Y, Walker R and Hong I (2017) 'Subjective experiences of older people in poverty in urban China and the role of social policy', Asia Pacific Journal of Social Work and Development, 10.1080/02185385.2017.1358660

Edmonds EV (2005) Targeting child benefits in a transition economy. Economics in Transition 13(1): 187-210.

Finn D, Mason D, Rahim N and Casebourne J (2008) Problems in the delivery of benefits, tax credits and employment services, York: Joseph Rowntree Foundation;

[http://www.jrf.org.uk/publications/problems-delivery-benefits-tax-credits-and-e mployment-services].

Gao J and Huang Z (2007) The characteristics of five guarantees system in rural China: Relationship between state and community. Social Science 6: 64-71. (in Chinese)

Golan J, Sicular T, and Umapathi N (2014) Any guarantees? China's rural minimum living standard guarantee program, Washington: World Bank, Social Protection and Labor, Discussion Paper 1423

Gray KA (2005) Pride, prejudice, and a dose of shame: The meaning of public assistance. Affilia 20 (3): 329-45.

Hernanz V, Malherbet F and Pellizzari M (2004) Take-up of welfare benefits in OECD countries: A review of the evidence, Paris: OECD, Social, Employment and Migration Working Papers 17.

Spicker P (1984) Stigma and Social Welfare. London: Groom Helm.

Stuber J and Schlesinger M (2006) Sources of stigma for means-tested government programs. Social Science \& Medicine 63: 933-45.

Jo YN (2013) Psycho-social dimensions of poverty: When poverty becomes shameful. Critical Social Policy 33(3): 514-31.

Jo YN and Walker R (2014) Self-sufficiency, social assistance and the shaming of poverty in South Korea, Pp. 61-84 in Gubrium E, Pellissery S, \& Lødemel I (eds.) The Shame of It: Global perspectives on anti-poverty policies. Bristol: Policy Press.

Krause N (1996) Welfare participation and self-esteem in later life. Gerontologist 36(5): 665-673.

Li M and Walker R (2016). Targeting social assistance: Dibao and institutional alienation in rural China. Social Policy and Administration, 10.1111/spol.12261.

Li M and Walker R (2017). Shame, stigma and the take-up of social assistance: Insights from rural China. International Journal of Social Welfare 26(3): 230-38.

Lister R (2004) Poverty. Cambridge: Polity Press.

Liu JQ, Liu K and Huang Y (2016) Transferring from the poor to the rich: examining the regressive redistribution in Chinese social insurance programmes, International Journal of Social Welfare 25(2): 199-210. 
Michalopoulos C (2004) Welfare Time Limits in the United States, Munich: Ifo Institute for Economic Research CESifo DICE Report 2/2004, pp. 64 - 68.

Ministry of Civil Affairs (2006) Regulations for five guarantees. Retrieved 30 September 2016, from [http://www.mca.gov.cn/article/yw/shjz/fgwj/201507/20150700850248.shtml]. (in Chinese)

Ministry of Civil Affairs of P.R. (2016a) China. Statistics of recipients of Dibao in rural China (July 2016). Retrieved 20 September 2016, from [http://www.mca.gov.cn/article/sj/tjjb/dbsj/201607/2016021120.html]. (in Chinese)

Ministry of Civil Affairs of P.R. China. (2016b) Statistics of the development of social service 2015. Retrieved 20 September 2016, from [http://www.mca.gov.cn/article/sj/tjgb/201607/20160700001136.shtml]. (in Chinese)

National People's Congress (1957) The outline of national agricultural development 1956-1967. Beijing: People Daily Press. (in Chinese)

NIA (2011) Global health and aging. Bethesda: National Institute of Aging 11-7737.

Nicolas G and Baptiste VJ (2001) Experience of women on public assistance. Journal of Social Issues 57 (2): 299-309.

Oorschot van W (1991) Non take-up of social security benefits in Europe. Journal of European Social Policy 1(1): 15-30.

Oorschot van W (2006) Making the difference in social Europe: Deservingness perceptions among citizens of European welfare states. Journal of European Social Policy 16(1): 23-42.

Pellissery S and Mathews L (2014) 'Thick poverty, thicker society and thin state: Policy spaces for human dignity in India’, Pp.37-60 in Gubrium, E., Pellissery, S., \& Lødemel, I. (eds.) The Shame of It: Global perspectives on anti-poverty policies, Bristol: Policy Press.

Rank MR (1994) A view from the Inside Out: Recipients' perception of welfare. Journal of Sociology and Social Welfare 21(2): 27-47.

Roelen K and Gassmann F (2011) How effective can efficient be? Social assistance in Kosovo and what it means for children. Journal of European Social Policy 21(3): 238-52.

Sim A, Negara R, and Suryahadi A (2015) Inequality, elite capture, and targeting of social protection programs: Evidence from Indonesia, Jakarta: The SMERU Research Institute September.

Simpson R and Walker R (eds.) (1993). Europe: For Richer or Poorer? London: CPAG.

Span P (2013) When there's no family, New York Times, September 23, 12:10.

State Council (2007) Notice of the establishment of rural minimal living security system (Dibao) in China. Retrieved 30 September 2016, from [http://www.mca.gov.cn/article/zwgk/fvfg/zdshbz/200711/20071100003801.shtm 1]. (in Chinese)

Stuber J and Schlesinger M (2006) Sources of stigma for means-tested government 
programs. Social Science and Medicine 63: 933-945.

Tangney J and Dearing R (2003) Shame and Guilt. New York: Guilford Press.

Walker R (2005) Social Security and Welfare: Concepts and Comparisons. Maidenhead: Open University Press.

Walker R (2014) The Shame of Poverty. Oxford: Oxford University Press.

Wang H (2009) DINK in China and its socioeconomic influences. Studies of Productive Forces 16: 13-14+46. (In Chinese)

Williamson JB (1974) The stigma of public dependence: A comparison of alternative forms of public aid to the poor. Social Problems 22(2): 213-28.

Wang, F. and Liu, Y (2016) Interpreting Chinese Hukou System from a Foucauldian Perspective, Urban Policy and Research, http://dx.doi.org/10.1080/08111146.2016.1159190

Wong L (1998) Marginalization and Social Welfare in China. London: Routledge.

Wright S (2003) 'The street level implementation of unemployment policy', pp. 235-254 in Jane Millar (ed.) Understanding Social Security: Issues for policy and practice. Bristol: Policy Press.

Yaniv G (1997) Welfare fraud and welfare stigma. Journal of Economic Psychology 18: $435-451$.

\section{Corresponding author:}

Mianguan Li, Department of Law and Political Sciences, Zhejiang Normal University, NO. 688, Yingbin Street, Jinhua 321004, Zhejiang Province, PR. China.

E-mail: limianguan@126.com

\section{Author Biographies}

Mianguan Li, $\mathrm{PhD}$, is an associate professor in Department of Law and Political Sciences at Zhejiang Normal University, PR. China. His research focuses on social policy, social welfare, poverty and social work practice, especially on the relationship between poverty and the practice of social welfare, poverty and shame, etc. His recent publications include: With Walker, R. (2016) 'Targeting Social Assistance: Dibao and institutional alienation in rural China', Social Policy and Administration DOI: 10.1111/spol.12261; With Walker, R. (2017) 'Shame, stigma and the take-up of social assistance: Insights from rural China', International Journal of Social Welfare 26(3): 230-238. 
Robert Walker is Professor Emeritus and Emeritus Fellow of Green Templeton College at University of Oxford. He is a Fellow of the Royal Society of Arts and was awarded an MBE in 2012 for his services to social policy research. His current research includes two major international studies. The first, funded by the ESRC and DFID, seeks to establish whether 'shame-proofing' anti-poverty programmes, remodelling them to promote human dignity and to reduce stigma, improves their overall effectiveness. The second study, being undertaken with ATD Fourth World, is a deeply participative study working with people experiencing poverty in Bangladesh, Bolivia, Tanzania, Britain, France and the USA to the define the dimensions of poverty that should be considered within the framework of the Sustainable Development Goals. In addition, he is undertaking research exploring the representation of poverty in China through the medium of film. His recent publications include: With Li, M. (2016) 'Targeting Social Assistance: Dibao and institutional alienation in rural China', Social Policy and Administration DOI: 10.1111/spol.12261; With Li, M. (2017) 'Shame, stigma and the take-up of social assistance: Insights from rural China', International Journal of Social Welfare 26(3): 230-238. 
Table 1 Characteristics of Interviewees

\begin{tabular}{lrrrrrrrr}
\hline & $\begin{array}{c}\text { Dibao } \\
\text { recipients }\end{array}$ & \multicolumn{2}{c}{$\begin{array}{c}\text { Wubao } \\
\text { recipients }\end{array}$} & \multicolumn{2}{c}{$\begin{array}{c}\text { Non- recipients } \\
\text { (including } \\
\text { cadres) }\end{array}$} & \multicolumn{2}{c}{ All } \\
& N & \% & N & \% & N & \% & N & \% \\
\hline Age & & & & & & & & \\
$\quad$ Younger than 30 & 0 & 0 & 0 & 0 & 4 & 12 & 4 & 5 \\
$\quad 30-45$ & 3 & 11 & 0 & 0 & 11 & 32 & 14 & 19 \\
$\quad 46-60$ & 17 & 61 & 0 & 0 & 10 & 29 & 27 & 36 \\
$\quad$ Older than 60 & 8 & 29 & 12 & 100 & 9 & 26 & 29 & 39 \\
\hline Gender & & & & & & & & \\
$\quad$ Male & 16 & 57 & 8 & 67 & 19 & 56 & 43 & 58 \\
$\quad$ Female & 12 & 43 & 4 & 33 & 15 & 44 & 31 & 42 \\
\hline Total & 28 & 100 & 12 & 100 & 34 & 100 & 74 & 100 \\
\hline
\end{tabular}

Table 2 Comparison of Wubao and Dibao

\begin{tabular}{|l|c|c|}
\hline & Wubao & Dibao \\
\hline Nature of policy & $\begin{array}{c}\text { Social assistance, } \\
\text { alleviating poverty }\end{array}$ & $\begin{array}{c}\text { Social assistance, } \\
\text { alleviating poverty }\end{array}$ \\
\hline Targeting mechanism & Identity targeting & Income targeting \\
\hline Targeting group & $\begin{array}{c}\text { Elders, the disabled, } \\
\text { orphans who are poor }\end{array}$ & Anyone who is poor \\
\hline Source of funding & $\begin{array}{c}\text { From collective-based to } \\
\text { public finance supported }\end{array}$ & Public finance supported \\
\hline Guarantee standard & Higher & Lower \\
\hline Coverage & Narrow & Broad \\
\hline
\end{tabular}

Table 3 Wubao, Dibao, and stigma

\begin{tabular}{|l|l|l|}
\hline \multicolumn{1}{|c|}{ Types of stigma } & \multicolumn{1}{c|}{ Wubao } & \multicolumn{1}{c|}{ Dibao } \\
\hline Institutional & Cultural marginalization & Cultural inclusion \\
\hline Social & Social exclusion & No clear social exclusion \\
\hline Personal & Negation of self & Shame of poverty \\
\hline
\end{tabular}


